\title{
ABSTRACTS
}

\section{I. -RETINA}

( I) Sallmann, L. and Sveinsson, K. (Vienna).-On the vision and fields after successful operation in detachment of the retina. (Ueber Sehschärfe und Gesichtsfeld bei operativ geheilter Netzhautabhebung). Arch.f. Ophthal., Vol. CXXX, p. 1.

(1) Sallmann and Sveinsson here make an instructive contribution to the study of the visual acuity and fields in retinal detachment after operation. They collected 101 cases from Lindner's clinic successfully treated (i.e., with complete re-attachment of the retina) by the methods of Gonin, Guist and Lindner, and analysed them according to the duration of the disease and, as a basis of subdivision, the vision immediately preceding operation.

Asiregards the central vision after successful operation the authors show that while improvement depends chiefly on the duration of the disease, operation should be given a trial even in detachments of 1 to $1 \frac{1}{2}$ years' standing, because in a large percentage of these cases useful vision can be obtained. Apart from the factor of duration, the prognosis for the vision is, as a rule, more favourable if, proor to operation, it has not sunk below the counting of fingers.

The size and character of the detachment, as well as the age of the patient, have no appreciable influence on the vision of these successful cases; nor has the position of the tears (or the site of the operation), apart from tears at the macula.

The number of operations necessary to effect a cure can have an unfavourable influence on the vision, if the operation has to be repeated more than three times.

In cases of tears at the macula the prognosis after operations with caustic potash is not so unfavourable as might be at first supposed.

None of the operative procedures here considered carries with it any risk as regards the non-improvement of central vision after operation. The cases treated with caustic cauterisation did not show any changes at the macula that could be regarded as a remote effect of the action of the caustic substance. After ignipuncture a remote reaction could not be definitely excluded in individual cases. Certain changes at the macula are associated with the use of caustic, but they are of no practical importance as they do no damage to the vision. Other macular changes are perhaps due to mechanical injury at the operation.

Dense vitreous opacities, causing low central vision, are most frequent after ignipuncture, and occur most seldom after the undermining operation. 
The vision obtained shortly after operation may further improve appreciably as time goes on through gradual recovery of the retina.

Investigations on the visual field show that after re-attachment of the retina it increases usually considerably and continues to do so, more rapidly and more fully in recent cases than in those of long standing.

As to colour vision the perception for red returns first, followed by that for blue earlier in recent cases than in old. In detachments of less than one year's standing the field for blue usually increases considerably, so that the physiological arrangement of the colour fields is ultimately attained. In old detachments the limit for blue remains smaller than that for red; in them blue is at first called green.

The later improvement in the field may continue for years.

In contrast to the duration of the disease, the age of the patient and the character of the detachment appear to have no influence on the recovery of the field, nor can too much importance be attached to the extent of the detachment.

While none of the operations offers any special advantage for improvement in the central vision, ignipuncture is less favourable as regards increase of the fields than the other methods, as with it considerable defects in the fields occur most frequently. Numperous repetitions of the trephine method cause an amount of damage that is not explained by the extent of the operation. An appreciable increase in the field with return of the colour sense may be obtained by the use of Lindner's Lochbrille after re-attachment of the retina.

The cases treated by the diathermy method were not included with the others, because the number was too small and the period under observation too short; as regards visual acuity and field, however, the results from this operation were not materially different from those obtained by other methods.

Thos. SNOWball.

(2) Kleiner, Leo (Vienna).- The intra-ocular tension in detachment of the retina. (Der intraoculare Druck bei Netzhautablösung). Arch.f. Ophthal., Vol. CXXIX, p. 485.

(2) The study of the tension in retinal detachment has been pursued for many years, at first by palpation with the fingers and later by means of the tonometer, with varying results. Interest in this question has been revived in recent years through the success that has followed the operative treatment of this condition.

Kleiner has in this paper analysed the tonometric readings he obtained from a large number of cases in Lindner's clinic, and arranged them in tables to illustrate different points.

The results of his investigations are:-

1. The difference in tension between the affected and the normal eye, without distinction between fresh and late cases, amounted on the average to $4 \mathrm{~mm}$. $\mathrm{Hg}$. 
2. In nearly three-fourths of all the cases, whether recent or old, the tension in the eye with detachment is lower than that in the other. (It is interesting to note that in a few cases, the author, like other observers, found the tension in the affected eye slightly higher than in the unaffected.)

3. Fifty per cent. of all the affected eyes are hypotonic (i.e., gave readings of less than $16 \mathrm{~mm} . \mathrm{Hg}$ ).

4. The fall in tension is approximately proportional to the age of the detachment.

5. A rise in tension was found in 66 per cent. of the cured cases, tested within four weeks after the operation.

6. The degree of myopia has no practical influence on the tension of an eye with detached retina.

7. The more extensive the detachment (or the larger or more numerous the tears in the retina), the greater the difference in tension between the affected and the normal eye, and the more frequently hypotony occurs.

8. After a period of at least four months after cure of the detachment the tension is usually the same in the two eyes.

The readings obtained in this series of cases, in the author's opinion, furnish further proof of the views put forward by Leber as to the absorption of the fluid in the vitreous by the capillaries of the choroid and by Lindner on the mechanism of detachment of the retina.

Thos. SNOWBal.l.

(3) Arruga, H. (Barcelona).-Personal experiences in the treatment of detachment of the retina and a description of recent operative procedures. (Experiencia personal sobre el tratamiento del desprendimiento de la retina y descripción de sus recientes modalidades operatorias). Arch de ()ftal. Hisp.Amer., Vol. XXXII, No. 11, p. 614, November, 1932.

(3) In this paper Arruga speaks of his own operative results, mainly obtained with the thermo-cautery and by trephining, and also gives a clear and exhaustive account of the principal operations in use for detachment at the present time. l3etween 1928 and 1932 he saw 216 cases of detachment, of which only thirteen were secondary (intra-ocular tumour, uveitis, metastatic choroiditis and von Hippel's disease). He operated on 164, obtaining cures in 53 . He has developed certain points of technique, of which the most noteworthy is the fixation of the eye after the operation by means of a suture through the lower lid and the tendon of the inferior rectus. He attaches the utmost importance to the maintenance of immobility after the operation. He has also an ingenious instrument in the form of a.small screw which can be inserted into a trephine hole to block it temporarily in cases where the choroid has been 
accidentally perforated and the operation would otherwise have to be abandoned.

A large part of the paper is taken up with a resume of the work of Guist, Lindner, Weve, Safar, Clausen, Meller and others on the subject.

IDA MANN.

(4) Arruga, H. (Barcelona).-Experimental adhesive choroiditis. (La coroidite adesiva sperimentale). Ann. di Ottal., July, 1932.

(4) The mechanism by which Gonin's operation produces a closure of the retinal hole is a matter on which different opinions have been held. Arruga has investigated the sequence of events which follow the various procedures belonging to Gonin's and the allied operations. His experiments have been conducted for the most part on rabbits, but some few have been undertaken on eyes which demanded enucleation; this operation being postponed for a few days to see the effects of the cautery puncture.

Arruga finds the sequence of events varies considerably with the method used; after a cautery puncture applied very rapidly the effects are limited; there is swelling of the sclerotic immediately at the wound, but the choroid and retina show little change. The wound is filled by a plug of vitreous which adheres to the episcleral tissues. The retina gradually forms adhesions to the edges of the wound within six or seven days. Two months after the operation the hole is occupied by fibrous tissue which appears to be a continuation of the sclerotic. The adhesion of the choroid and retina to the edges of the hole appears to be very strong. There is apparently no change in the retina beyond the adherent area.

On the other hand, when the action of the cautery is more prolonged, the surrounding tissues are changed by the heat in varying extent according to the duration of the application.

Chemical cauterization, after trephining the sclerotic (Guist's operation), is followed by extensive inflammatory reaction, varying with the concentration of the caustic and its nature. The adhesion following this reaction seems to be more solid than that produced by the actual cautery. The reaction following diathermy is often great and the over-lying retina is often destroyed; in shallow detachments this agent must be used with great caution.

\section{Harold Grimsdale.}

(5) Lumbroso (Rome).-Wounds of the retina. (Le ferite della retina). Rass. Ital. d'Ottal., November and December, 1932.

(5) Lumbroso has investigated the course of wounds in the retina, using rabbits as the subject of his experiments; he was careful to avoid injury to the subjacent choroid, passing the needle 
with which he lacerated the retina through the sclerotic about 5 $\mathrm{mm}$. above the corneal margin, and watching the course of the point through the eye by means of an ophthalmoscope until it reached the retina below the optic disc. The eyes were removed at varying dates after the injury, and the changes carefully noted. Lumbroso finds that there is never recovery of the injured part, but always a more or less extended area round the seat of injury which suffers degeneration.

HaROLd GRIMSDALE.

(6) Agnello (Syracuse). - Retinitis proliferans following an indirect injury to the eye. (Retinite proliferante per trauma indiretto dell'occhio). Lett. Oftal., October, 1932.

(6) This case was that of a soldier who was wounded in the leg and fell, striking the left side of his forehead against a rock thus producing a large contused and lacerated wound. He noticed dimness of vision soon after, and in 1922 was discharged from the army; it was then noted that he had retinitis proliferans. This was regarded as not being attributable to the war injury.

Agnello gives his reasons for thinking this judgment incorrect.

Harold GRIMSDale.

(7) Jaffe, Morris and Schonfeld, William A. (New York).Lipaemia retinalis due to diabetes mellitus. Arch. of Ophthal., April, 1933.

(7) Lipaemia retinalis is a rare condition as shown by the observation that lipaemia develops in less than 7 per cent. of diabetics and that in 150 cases of lipaemia there were only two of lipaemia retinalis. Various theories are quoted by Jaffe and Schonfeld to account for the occurrence of the condition, but none is entirely satisfactory. Bloor believes that it is due to deficiency of a hormone whose function it is to aid in the removal of fat from the blood to the tissues; Allen that in the cachexia accompanying severe diabetes there is interference with the permeability of the cell walls which prevents the passage of fat through them and so leads to its accumulation in the blood; Muskat that it is an attempt to mobilise excessive quantities of fat in order to make up for the defective power of oxidising carbohydrates. Lipaemia retinalis occurs more commonly in young subjects, the average age of those affected being 25, with extremes of 9 and 50 years. The creamy. pink colour of the vessels in this condition is not yet certainly explained. It may be due to segregation of the red cells in the middle of the blood stream so that there is a peripheral portion which is opaque, or to accumulation of fat in the adventitia or of 
fatty lymph in the peri-vascular lymph spaces. In all probability acidosis is a necessary concomitant to the occurrence of lipaemia retinalis and it was present in the case described by the authors.

$$
\text { F. A. W-N. }
$$

(8) Ask-Upmark, Eric (Lund, Sweden).-On the cortical projection of the temporal half-moon of the visual field. Acta Ophthal., Vol. X, p. 271, 1932.

(8) Ask-Upmark reviews the literature on the cortical representation of the retina and reports a case of circumscribed cortical tuberculoma in the cuneus with loss of the temporal field. From a profusely illustrated and detailed analysis it is concluded that the cortical projection of the nasal retina is in the anterior part of the calcarine region, probably around the confluence of the calcarine and parieto-occipital fissures. Contrary to the general belief, it is held that the upper half of the nasal retina is represented in the superior lip of the calcarine fissure, and the lower half in the inferior lip. Macular projection is nearer to the vertex of the occipital lobe, this being in agreement with the phylogenetic view which regards macular vision as a late acquisition.

ARNold Sorsby.

\section{II.-GLAUCOMA}

(I) Werner, S. (Helsingfors).-The effect of subcutaneous injection of Gynergen (Ergotamin) on the tension in glaucoma: (Ueber die Einwirkung subcutaner Gynergen(Ergotamin)- Injektionen auf den Druck bei Glaukom).

Clinical investigations on the effect of subconjunctival injection of Gynergen on the tension in glaucoma. (Klinische Untersuchungen ueber die Einwirkung von subconjunctivalen Gynergininjektionen auf den Druck bei Glaukom). Acta Ophthal., Vol. IX, pp. 275 and 286, 1931.

(1) Werner reports an investigation in 15 patients $(25$ glaucomatous eyes) on the effect of subcutaneous injection 0.5 c.c. t. i. d. of ergotamin on ocular tension. Only in five eyes was there any lowering of tension; this treatment did not re-inforce the action of miotics. In 16 cases (18 glaucomatous eyes) the drug was used subconjunctivally. In 14 eyes the tension was lowered, in two it was unaffected and in two raised, the best results with subconjunctival injection were obtained in glaucoma simplex, and though satisfactory they are not so good as those that can be obtained by means of adrenalin and miotics.

ArNold Sorsby. 
(2) Fialho, Abreu (Rio de Janiero). - Contributions to the treatment of chronic glaucoma. (Beiträge und Erläuterungen zur chirurgischen Behandlung des chronischen Glaukoms). Zeitschr. f. Augenheilk., Vol. LXXVI, p. 346, 1932.

(2) Fialho discusses the technical difficulties of the trephine operation and proposes two modifications: (1) In cases in which the tension is high and is not controlled by miotics it is advisable to compress the eye to the extent of $150 \mathrm{~mm} . \mathrm{H}_{2} \mathrm{O}$ for 10 minutes before operation. The lowering of tension thus produced is variable but is always useful. (2) To facilitate the iridectomy the trephine hole should be enlarged in one direction to $3.5 \mathrm{~mm}$. by means of a knife.

\section{ARNOLd SORSBY.}

(3) Zanettin (Padua).-Perception of luminosity in macular and peripheral vision, in chronic primary glaucoma. (Comportamento del senso luminoso centrale e periferico nel glaucoma cronico semplice). Ann. di Ottal., September and October, 1931.

(3) The little work that has been done on the subject of the behaviour of the luminous sense in glaucoma, says Zanettin, has been confined almost exclusively to the study of the central region. In this paper he publishes the results of his observations on a number of glaucomatous eyes.

Lo Cascio has shown that there is a zone round the macula which is less sensitive to light than the macula. From this point, the sensitiveness increases to reach the maximum about $30^{\circ}$ or $40^{\circ}$ from the centre. Beyond this, it again diminishes.

From his observations, Zanettin finds that in glaucoma the sensitiveness to light is much reduced all over the retina, but the peripheral zone suffers relatively more than the central. He finds that the temporal retina (corresponding to the nasal field) is the first to suffer and then the superior, inferior and nasal areas in that order. The reduction of sensitiveness seems to have a relation to the intra-ocular pressure.

The author regards the alteration in the light sense as a very early symptom of glaucoma.

\section{Harold Grimsdale.}

(4) Stenico (Florence).- First studies on the presence of histaminoid substances in the aqueous of glaucoma. (Primi tentativi sperimentali diretti alla ricerca di sostanze istamino-simili nell'umore acqueo dei glaucoma osi). Boll. d'Ocul., December, 1932.

(4) Opinion on the origin of the acute attack in glaucoma has of late inclined to regard it as to some degree comparable to an 
acute oedema, and requires for the onset, a predisposition of the vascular system and a toxin which excites the attack. Friedenwald has found in the aqueous of glaucoma a substance which injected subcutaneously produced a wheal similar to urticaria. Histamine has the power of producing similar lesions. Stenico, using a coil of intestine of a guinea-pig, finds it possible to detect histamine in solution of 1 in 500,000 , by alteration in character of contractions of the muscle. If there is an histaminoid substance present in the glaucoma aqueous, it could be detected in this way.

The author has experimented with the aqueous of a few patients and has found the reaction in one.

Harold Grimsdale.

(5) Alajmo (Catania).-Histamine, its action on the normal and on the glaucomatous eye. (L'anzione della istamina sull'occhio normale e sull'occhio glaucomatoso). Rass. Ital. d'Ottal., January, 1933.

(5) Histamine is an amine which is formed abundantly by putrefactive bacteria; it is very toxic. It brings about a collapse comparable to shock after operation. Its action on the vascular system is complicated; it causes vaso-constriction of the arteries but this is more than counterbalanced by dilatation of the capillaries, and the total result is a great fall in the blood pressure. Its action on the eye has not been carefully investigated and the present paper is based on experiments on animals and to some extent on man.

Alajmo concludes that histamine causes a local vaso-dilatation and chemosis of the conjunctiva; if injected into the anterior chamber in animals it causes an intense irritation with inflammation if the solution is concentrated. The pupil is contracted as a result of the vaso-dilatation of the iris. When injected intravenously. there is mydriasis and a fall in the intra-ocular pressure.

In glaucoma, instillation of a solution into the conjunctival sac is followed by an increase of pressure.

Harold Grimsdale.

(6) Biffis (Padua).- The alkalinity of the blood in glaucoma. (L'alcalescenza del sangue nel glaucomatosi). Ann. di Ottal., February, 1933.

(6) The modern developments of biochemistry have shown the probable importance of the reaction of the tissues whether acid or alkaline. The state of the vitreous gel has been supposed to be closely affected by the reaction of its humours; in this paper Biffis summarises recent work on the subject and adds some examinations of his own on the reserve of alkali in the plasma in normal and glaucomatous patients. He finds a slight increase in the alkalinity 
of the glaucomatous, though the average is not outside normal limits. Though the increase is small it must be taken into consideration, he thinks, since although it may not suffice to account for the whole syndrome of glaucoma, it may be an adjuvant to other conditions.

HAROLD GRIMSDALE.

(7) Biffis (Padua). - The relation between calcium and potassium in the blood in glaucoma. (Rapporto tra calcio e potassio nel sangue dei glaucomatosi). Ann. di Ottal., April, 1933.

(7) As the ions of hydrogen and hydroxil are opposed in their essential action, so also to some extent are the ions of calcium and potassium. Potassium seems to modify the body metabolism in the direction of alkalinity, while calcium tends to produce acidosis.

In this second paper Biffis gives the result of his examination of the blood of a number of glaucomatous patients. He finds a slight deficiency of calcium and a considerable increase of the potassium content; his conclusions are that the deficiency of calcium in the presence of the vitreous determines a lowering of the osmotic pressure and therefore an influx of water; this action is strengthened by the increase in the potassium.

A further result is an increase in alkalinity of the fluids in the tissues; this again favours the onset of glaucoma.

HAROLD GRIMSDALE.

\section{III.-MISCELLANEOUS}

(I) Kreibig, W. (Vienna).-On leukaemic fundus changes. (Ueber leukämische Fundus-veränderungen). Zeitschr. $f$. Augenheilk., Vol. LXXVI, p. 358, 1932.

(1) Kreibig reports a case of lymphatic leukaemia in which the symptoms of a cerebral tumour were present, and the fundi showed papilloedema and later on star formation at the macula, together with multiple small white retinal exudates peripherally. Postmortem a large subdural leukaemic infiltrate was found in the middle cranial fossa, but no leukaemic infiltrates could be found in the retinae, papilloedema and haemorrhages only being seen microscopically. The author holds that the fundus changes are to be explained by the increased intracranial pressure acting on a retina with vessels prone to bleed.

Arnold Sorsby. 
(2) Lugli. (Bologna).-Ocular lesions in experimental avitaminosis. (Lesioni oculari da avitaminosi A sperimentale). Rass. Ital. d'Ottal., January, 1933.

(2) The relation between xerophthalmia and the deficiency of vitamin A has been remarked for a considerable time; it is not clear, however, whether the lesions found are entirely due to the food deficiency or whether they are due to the coincidental attacks of pathogenic micro-organisms.

To clear up this and other points, Lugli adopted the plan of performing tarsorrhaphy on one side of the animals under investigation, before the feeding experiments were begun. In this way one eye was guarded against accidents from external bacteria. He found that when the tarsorrhaphy was complete, the protected eye showed changes in the epithelium but much less than the unprotected eye which in all cases suffered ulceration and perforation. He concludes that the more serious effects are due to bacterial infection, which is made more virulent owing to the changes in the epithelium.

Harold Grimsdale.

(3) Gertson and co-workers. (Grand Forks, N.D.).-Wohlfartia myiasis in North Dakota. Jl. Amer. Med. Assoc., February 18, 1933.

(3) Two cases of Wohlfartia infestation are reported, one of which is of the orbit. Gertson state that they have failed to find in the literature any report of orbital infection with the larvae of this fly Wohlfartia vigil (Walker). Had access to the Bulletin of the Ophthalmological Society of Egypt for 1917 been available they would have found a report of cases of "Fly-blown Orbit" by Barsoum, due to Wohlfartia Magnifica (Schinner). This fly is viviparous. It can settle on the conjunctiva for a fraction of a second, deposit a living larva, and fly away. The larva or larvae begin at once to eat a way into the orbit, and the condition unless it is recognised early, may cause terrible damage. It is not uncommon in Egypt.

A. F. MacCallan.

(4) Mayer, L. L. (Chicago). - Congenital reading disability. Jl. Amer. Med. A ssoc., April 15, 1933.

(4) This interesting article does not lend itself to full abstraction but some points may be alluded to. It is accompanied by a good bibliography of the subject with due reference to Morgan and to Hinshelwood. The first mention of ocular dominance found in the literature was made by Porta in 1593. This is an important feature in acquired, congenital and partial word blindness. Porta 
noted that right-handed individuals preferred to use the right eye to the exclusion of the left eye when aiming. Among the methods of testing ocular dominance is to look at the middle letter of the $6 / 24$ line of the Snellen test-type, to point your finger at it and then close the left eye. If you are right-eyed you are covering the letter accurately, if you are left-eyed you are not. It has recently been shown in the lay press that stammering is especially common among left-handed children who have been taught to use their right hands for writing. Loss of nervous balance may be produced in this way. B. S. Parson, a great authority on this subject, in studying a large group of school children reports that out of 877 , 29.3 per cent. were left-eyed; of 608 who were right-eyed, 99.5 per cent. were right-handed; of 257 who were left-eyed only 12.4 per cent. were left-handed. Orton states that the master eye is a safer guide to native dominance than the master hand. It is of interest to note that in his Bradshaw Lecture in 1932 the late revered Herbert Fisher stated his opinion that the idea of a master eye was a fallacy. Those who are interested in this subject should not neglect Macdonald Critchley's paper before the Section of Neurology of the Royal Society of Medicine on Dec. 9th, 1926.

\section{A. F. Maccallan.}

(5) Llorca, J. P. (Cadiz).-Contribution to the origin and nature of the vitreous body. (Contribucion al origen y naturaleza del cuerpo vitreo). Arch. de Oftal. Hisp.-A mer., Vol. XXXII, No. 10, p. 540, October, 1932.

(5) In a painstaking paper Llorca re-opens the perennial controversy concerning the origin of the vitreous. He considers that he can bring forward further arguments in favour of the participation of the vascular mesoderm in the formation of the vitreous, not only in mammals but also in birds although this has recently been denied by Redslob. The paper is divided into four sections and a bibliography. The first section deals with previous work and affords a résumé of present views on the subject. The second enumerates the material and methods employed. The third, illustrated by numerous micro-photographs, is a record of the author's personal observations, while the fourth deals with his interpretations and conclusions.

The material employed consisted of chick embryos in series up to the sixth day, as well as of rabbit, guinea pig and calf embryos. Various methods of fixation were employed to obviate artefacts due to any one solution. Simple, differential and impregnation methods of staining were used.

The author concludes in the first place that the vitreous is not a true tissue, the cells within it being merely included, not an essential 
part of it. Secondly, he sees no reason to suppose it a secretion of the retinal or lentine epithelium since, although vitreous fibrils may appear strongly attached to either of these layers, they are attached more strongly still to the walls of the intra-ocular blood vessel (hyaloid or artery of the pecten as the case may be). He therefore considers the vitreous to be a transudate, more or less altered by unknown circumstances. It appears first in the neighbourhood of the vessels even in birds, in which the intra-ocular vessel remains small and confined to the lower part of the eye and its fibrils always remain attached to vascular remnants or to the pecten, itself a vascular structure.

IDA MANn.

(6) Krug, Ernest F. and Rohdenburg, G. L. (New York).Foreign substances injected into the vitreous of the rabbit. Arch. of Ophthal., July, 1932.

(6) Krug and Rohdenburg begin their paper with a survey of our present knowledge of the pathway from one eye to its fellow. In 1924 Mariani inoculated three rabbits with the scrapings from herpetic keratitis with resulting inflammation in the fellow eye in 16-18 days. In 1927 von Szily demonstrated histologically that the infiltration extended from eye to eye along the optic tract. Deutschmann in 1903 obtained the eyes, optic tracts and chiasma from a patient who suffered from sympathetic ophthalmitis and died from gastric carcinoma. The meninges, brain and ciliary nerves were normal while both optic tracts and the chiasma showed round-celled infilI ration. The authors of this paper injected various substances into the vitreous of a series of rabbits' eyes with the following results:(i) Various oils pigmented by Scharlach $R$. These showed that the pathway of the intra-ocular fluids was from the vitreous to the retina, between the cells of the retina to the choroid, through the lymph-clefts of the nerve, particularly those about its sheath and about the central blood vessels, to the chiasma and so down the opposite nerve to the fellow eye. (ii) Indian ink particles were taken up by wandering cells some of which after seven days had passed up the optic nerve, through the chiasma and down to the nerve head of the opposite eye. (iii) Kieselguhr appeared to travel even more quickly and wandering cells carrying particles of this substance were found in the nerve head of one eye within five days of injection into the vitreous of the fellow eye. Living streptococci (viridans) and living tubercle bacilli injected in the vitreous, produced marked inflammatory changes with resulting plastic exudate covering the nerve head. This exudate acted as a mechanical barrier to the passage of the organisms down the lymph spaces of the optic nerve.

'F. A. W-N. 
(7) Weekers, L. (Liège).-Ophthalmotonic reactions following experimental puncture of the ciliary body. (Réactions ophtalmotoniques expérimentales par piqure du corps ciliare). Arch. d'Ophtal., January, $193 \dot{2}$.

(7) Lesions which involve the ciliary body, whether inflammatory or traumatic, lead frequently to notable modifications of intra-ocular pressure. The derangement consists sometimes of augmentation, sometimes of diminution of tension. Neither the nature nor the mechanism of the change is clearly understood.

In a paper published some years ago, Pesme and Duthil recorded the results of experiment on a rabbit: with a very fine needle they punctured the eyeball about $1 \mathrm{~mm}$. from the limbus over the ciliary body. The needle was withdrawn sharply and escape of aqueous avoided. This experimental trauma induced an immediate fall in intra-ocular pressure; in 8 minutes it had dropped from $25 \mathrm{~mm}$. to $10 \mathrm{~mm}$. of $\mathrm{Hg}$, and this hypotonus persisted for 36 hours. The authors suggested that the rapidity of the phenomena could be explained only by nerve influence; that the puncture of the ciliary body provoked an active and prolonged uveal vaso-constriction leading to diminished blood-flow into the eyeball, and consequent hypotonus.

Weekers has made similar but more numerous experiments and has been led to conclusions concerning the cause of the hypotonus which differ widely from those just quoted. He observed a similar rapid lowering of intra-ocular pressure after puncture of the ciliary body, lasting for 48 hours. By the use of subcutaneous injections of fluorescein he satisfied himself not only that vaso-constriction is not induced but that vaso-dilatation occurs. The colouring matter passed into the punctured eveball much more freely than into its untouched fellow. Careful examination, under magnification, of the site of puncture, even when made by oblique insertion of the finest needle, always revealed evidence of leakage from the perforation.

In his experiments Weekers has noted varying results of this form of trauma: thus he has found an absence of immediate hypotonus but after a few hours a noticeable and prolonged lowering of pressure: again he has obtained a brief elevation of pressure followed by a hypotonic phase of more than 24 hours duration. These variations of pressure, in his opinion are characteristic of the ophthalmotonic reactions following puncture of the ciliary body.

It is possible to induce derangement of ocular tonus in very varied ways: by massage, by compression or contusion of the globe, by cauterisation of the sclera, by puncture of the iris, etc.

In an earlier paper Weekers published a critical study of this subject and attempted to elucidate the general laws which control experimental ophthalmotonic reactions, both direct and consensual. $H$ is conclusions are, briefly: all the procedures adopted consist 
essentially in traumatism of the eyeball. When this is severe it induces sudden and intense vaso-dilatation, a veritable turgescence of the uvea; the wall of the globe being rigid, a rapid augmentation of its contents is followed by rise of pressure. But this hypertonus is of short duration and is succeeded by lowered pressure lasting as long as the former hypertonus. If the trauma is less severe, and the uveal congestion less intense, the initial phase of hypertonus is slight and short; it may pass unperceived and only the phase of hypotonus be manifest.

The consensual modifications of intra-ocular tension in the non. traumatised eye, are due to reflex vaso-dilatation, but though similar they are much less in degree than those of the wounded eyeball; they may fail to be apparent except when the direct reactions to the injury have been severe.

Experimental ophthalmotonic reactions such as are here described, may be observed clinically in certain contusions of the eyeball.

\section{J. B. LAWFORD.}

(8) Giuffrida (Novara). - The prevention of industrial blindness. (Sulla prevenzione degli infortuni agli occhi nell' industria). Ann. di Ottal., July, 1932.

(8) The loss to industry from accidents to the eyes of workmen, is very great and could be prevented in large measure by the use of suitable protection. Unfortunately, from one cause or another many workmen are unwilling to use the protection which is provided for them and has been proved to be effectual.

The reasons for this are not far to seek; the goggles are often not comfortably adjusted to the individual, they necessarily reduce the visual field and to some extent the visual acuity since the surface is often clouded by moisture and also becomes, in course of time, scratched by the flying splinters which are constantly striking the surface.

Giuffrida shows that the loss of working time due to accidents to the eyes in a large metal works in Piedmont, was one-tenth of the time lost through all accidents.

Even when the injury is superficial, immediate skilled care is very necessary; removal of foreign bodies by unskilled hands is not infrequently followed by infection of the cornea and dangerous ulceration. Since the workmen have been ordered to consult the medical staff after all injuries to the eyes, however slight, there has been a considerable reduction in the time lost from these accidents.

Harold Grimsdale. 